\title{
Clinico-Pathological Spectrum of Gastrointestinal Malignancies in Jaipur Region
}

\author{
Ankita Kakani ${ }^{*}$, Ajay Yadav ${ }^{2}$ \\ ${ }^{1 *}$ Resident, ${ }^{2}$ Professor \& Head, \\ Department of Pathology, S.M.S. Medical College \& Hospital, Jaipur, Rajasthan, INDIA.
}

\begin{abstract}
Introduction: Tumors of the gastrointestinal tract are some of the common neoplasms encountered. They demonstrate an array of histological patterns, protean clinical presentations, an assortment of gross patterns and an immense variability in their prognosis with marked epidemiological differences in various geographic and ethnic populations. The objective of current study was to study the age, sex, site and to analyze variations in histopathological patterns of gastrointestinal malignancies.
\end{abstract}

Methods: Our study was laboratory based descriptive type of observational study. The specimens were kept in 10\% formalin overnight and further processed using automatic tissue processor. Staining was performed using Haematoxylin and Eosin stain.

Result \& Discussion: A total of 15,000 histological specimens were received during the study period out of which $145(0.97 \%)$ were cases of Gastrointestinal tract (GIT) malignancies. Males outnumbered females with a male to female ratio of 1.59:1. The most common age group affected was 46-60 years and commonest site was colon and rectum $(40 \%)$.Adenocarcinoma was the commonest histopathological diagnosis $(75.9 \%)$ followed by squamous cell carcinoma

\section{INTRODUCTION}

Worldwide gastrointestinal malignancies are a leading cause of both mortality and morbidity with marked epidemiological differences in various geographic and ethnic populations. ${ }^{1}$ Colorectal cancer ranks third among most common tumors of the world, according to World Cancer Report of 2014. ${ }^{2}$ Histopathology is the gold standard in the diagnosis of gastrointestinal tumors. Although adenocarcinomas are the predominant histopathological variant, there are wide histopathological variations in gastrointestinal malignancies. ${ }^{1}$ Carcinoma of esophagus is the eighth most common cancer in the world. ${ }^{3}$ The most common carcinoma of the esophagus is squamous cell carcinoma (adults over 50 years). ${ }^{4}$ Adenocarcinoma predominantly arises from Barrett's esophagus. ${ }^{5}$ Gastric cancer was the fifth commonest cancer in the World ${ }^{2}$ and $60 \%$ of them occurred in developing countries. Gastrointestinal stromal tumors (GIST) make the most of gastrointestinal mesenchymal neoplasms. GIST accounts for $2.2 \%$ of malignant gastric tumors. ${ }^{6}$ Although the small bowel represents $75 \%$ of the length of the alimentary tract, tumours comprise only $3-6 \%$, with slight predominance of benign tumors. ${ }^{4,7}$ Adenocarcinoma of the colon is the most common malignancy of the $\mathrm{GI}$ tract and is a major cause of morbidity and mortality worldwide. Virtually $98 \%$ of all cancers in the large intestine are
(12.4\%). Rare cases of Hodgkin's lymphoma $(\mathrm{HL})$ and metastatic renal cell carcinoma were also reported. We also came across cases of malignant gastrointestinal stromal tumor (GIST), non-Hodgkin's lymphoma (NHL), carcinoid tumor and malignant melanoma at different anatomical location of gastrointestinal tract.

KEYWORDS: Adenocarcinoma, Gastrointestinal malignancy, Hodgkin's lymphoma, Squamous cell carcinoma.

\section{${ }^{*}$ Correspondence to:}

Dr. Ankita Kakani, Department of Pathology, SMS medical college, Jaipur, Rajasthan.

Email: kakani.ankita23@gmail.com

Article History:

Received: 02-05-2016, Revised: 10-05-2016, Accepted: 19-05-2016

\begin{tabular}{|l|c|}
\hline \multicolumn{2}{|c|}{ Access this article online } \\
\hline Website: & Quick Response code \\
www.jimrp.com & \\
\hline DOI: & \\
10.21276/ijmrp.2016.2.3.027 & \\
\hline
\end{tabular}

adenocarcinomas. ${ }^{4}$ Colorectal cancer incidence peaks at 60 to 70 years of age, and fewer than $20 \%$ of cases occur before age 50 . Males are affected slightly more often than females. Colorectal carcinoma is more prevalent in the developed countries. Anal canal carcinoma (ACC) comprised 1.5 to $4 \%$ of large bowel cancers. Squamous cell carcinoma (SCC) is the most common anal canal neoplasm. ${ }^{8}$

\section{OBJECTIVES}

- To find the histopathological patterns of GIT malignancies in study group \& proportion of GIT malignancies among all histological specimens received at tertiary health care center.

- To study the age, sex, site of GIT malignancy in study group.

\section{MATERIAL AND METHODS}

This was a 18 months laboratory based, descriptive type of observational study carried out at department of pathology, S.M.S Medical College, Jaipur from January 2014 to June 2015.

Total 15,000 specimens were received for histopathological examination during this period, out of these 145 specimens were of gastrointestinal malignancy. The specimens were either a biopsy or a radical specimen. Biopsies measuring less than $3 \mathrm{~mm}$ dimension were excluded from the current study. 
The specimens received were fixed in $10 \%$ formalin overnight, grossed, and processed in automated tissue processor. Routine haematoxylin and eosin staining was performed, as and when required special stains like mucicarmine stain, periodic acid schiff's stain and immunohistochemistry (IHC) were also employed. Sections were examined under the light microscope and analysed.

Statistical analysis: The results were statistically analyzed by Pearson's Chi-square test. $P$ value of $<0.05$ was taken as statistically significant. Data analysis was performed by Software MiniTab Version 14.0.

\section{RESULTS}

Total 15,000 surgical specimens were received for histological examination during 18 months of study period. Among these 3238 (21.58\% of total specimen) were gastrointestinal tract samples. Total gastrointestinal malignancy cases were $145(0.97 \%$ of total specimens). Tumors of GIT showed wide variation in age distribution, with maximum number of patients between 46-60 years. Mean age of incidence of tumors of GIT is $49.95 \pm 15.40$ years (Table 1). Out of 145 cases, 89 were male and 56 were female.
The male:female ratio was 1.59:1. The commonest site of occurrence of tumors of GIT was the colon and rectum which constituted $40 \%$ of all cases and least common site was the Appendix (2.8\%). The most common clinical presentation was weight loss and anorexia (84.1\%) followed by fatigue $(71.7 \%)$ and abdominal discomfort (57.9\%).

Majority of the lesions, on gross examination, were of ulceroproliferative type.

Adenocarcinoma comprised the main bulk of G.I.T. malignancies and the most common site was colon and rectum followed by small intestine, stomach and anal canal. Squamous cell carcinoma was most common in esophagus followed by anal canal (Table 2).

Esophageal malignancies were commonly seen in lower third of esophagus $(61.9 \%)$ whereas least common site was upper third of esophagus (9.5\%).

Majority of gastric tumors were situated at pylorus (56.5\%), followed by body $(34.7 \%)$ and least common site was fundus $(8.7 \%)$ of stomach.

In our study majority of carcinoma were of moderately differentiated type $(72.6 \%)$ followed by poorly differentiated type $(16.4 \%)$.

Table 1: Age distribution of various histopathological diagnosis

\begin{tabular}{|c|c|c|c|c|c|c|c|c|c|c|}
\hline & 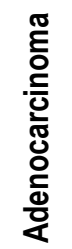 & 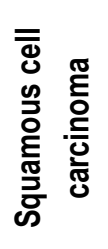 & $\frac{5}{\omega}$ & 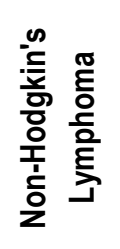 & $\begin{array}{l}\frac{.0}{0} \\
\frac{\text { 음 }}{\sqrt[J]{J}}\end{array}$ & 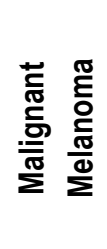 & 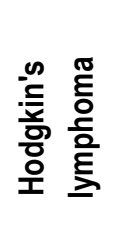 & 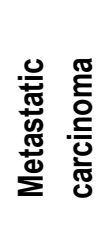 & 퓽 & 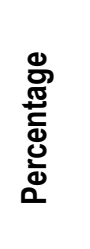 \\
\hline $1-15$ years & 1 & 0 & 0 & 0 & 0 & 0 & 0 & 0 & 1 & $0.68 \%$ \\
\hline $16-30$ years & 17 & 0 & 0 & 0 & 1 & 0 & 0 & 0 & 18 & $12.4 \%$ \\
\hline $31-45$ years & 34 & 3 & 2 & 1 & 0 & 0 & 1 & 0 & 41 & $28.3 \%$ \\
\hline $46-60$ years & 36 & 7 & 2 & 3 & 2 & 1 & 0 & 0 & 51 & $35.2 \%$ \\
\hline $61-75$ years & 18 & 7 & 1 & 0 & 0 & 2 & 0 & 0 & 28 & $19.3 \%$ \\
\hline $76-90$ years & 4 & 1 & 0 & 0 & 0 & 0 & 0 & 1 & 6 & $4.1 \%$ \\
\hline Total & 110 & 18 & 5 & 4 & 3 & 3 & 1 & 1 & 145 & $100 \%$ \\
\hline
\end{tabular}

Table 2: Distribution of type of Malignancy according to site $(\mathrm{N}=145)$

\begin{tabular}{|c|c|c|c|c|c|c|c|c|}
\hline Type of Malignancy & 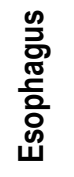 & 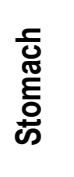 & 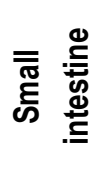 & $\begin{array}{l}\frac{x}{\overline{0}} \\
\frac{\overline{0}}{0} \\
\frac{0}{0}\end{array}$ & 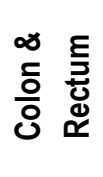 & 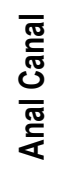 & i & 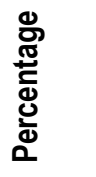 \\
\hline Adenocarcinoma & 4 & 21 & 22 & 2 & 54 & 7 & 110 & 75.9 \\
\hline Squamous Cell Carcinoma & 17 & 0 & 0 & 0 & 0 & 1 & 18 & 12.4 \\
\hline GIST & 0 & 1 & 4 & 0 & 0 & 0 & 5 & 3.4 \\
\hline Non-Hodgkin's Lymphoma & 0 & 0 & 3 & 0 & 1 & 0 & 4 & 2.8 \\
\hline Carcinoid & 0 & 1 & 0 & 2 & 0 & 0 & 3 & 2.1 \\
\hline Malignant Melanoma & 0 & 0 & 1 & 0 & 2 & 0 & 3 & 2.1 \\
\hline Hogdkin's Lymphoma & 0 & 0 & 1 & 0 & 0 & 0 & 1 & 0.7 \\
\hline Metastatic Carcinoma & 0 & 0 & 0 & 0 & 1 & 0 & 1 & 0.7 \\
\hline Total & 21 & 23 & 31 & 4 & 58 & 8 & 145 & 100.0 \\
\hline
\end{tabular}

Chi-square value $=179.274, \mathrm{df}=35, \mathrm{P}=0.000$, Significant 


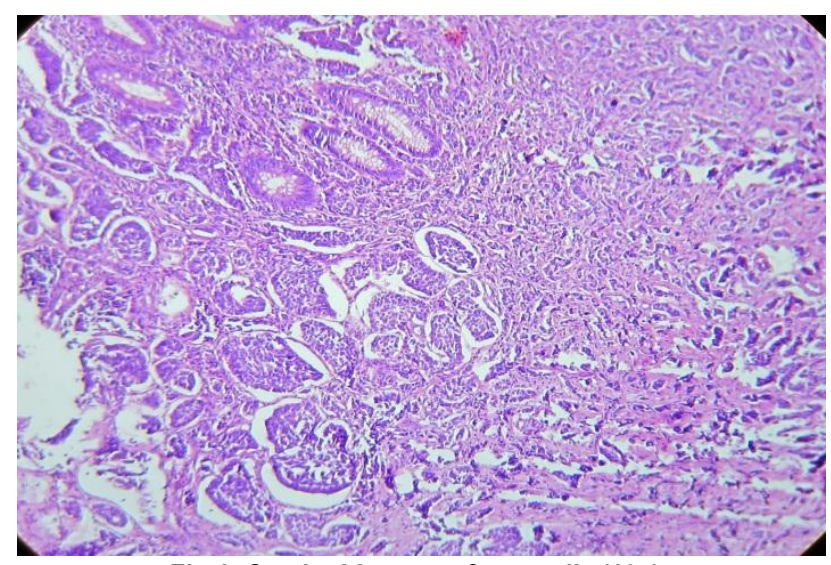

Fig 1: Carcinoid tumor of appendix (10x)

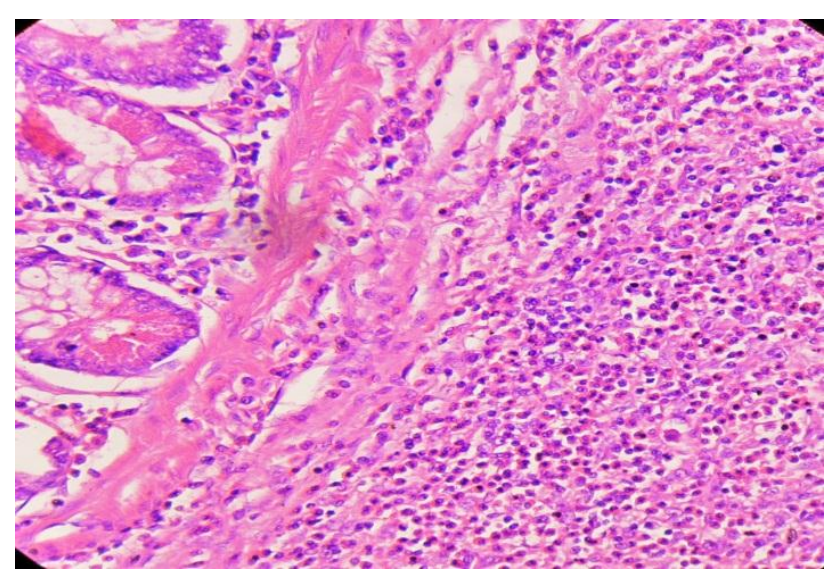

Fig 3: Hodgkin's Lymphoma involving small intestine(40x). Numerous eosinophils are seen.

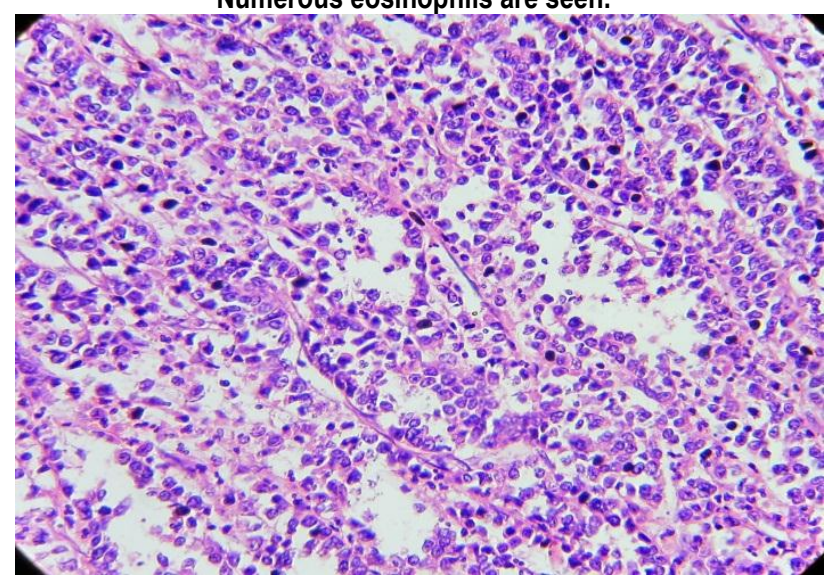

Fig 5: Metastatic Renal cell carcinoma in colon (40x)

\section{DISCUSSION}

The current study was undertaken at the Department of Pathology, SMS medical college, Jaipur. The total numbers of GI malignancy cases received from January 2014 to June 2015 (18 months) were 145 . GI malignancies were seen over a wide range of age ( 15 years to 85 years)and maximum were observed between 46 - 60 years (35.17\%) which was consistent with the study by Purohit MB et al. ${ }^{1} \mathrm{~A}$ male predominance was noted with male to female ratio of $1.59: 1$ commensurable with other studies. $1,9,10$

Several factors are contemplated for this rise in malignancy, including increase in hospital attendance, change in dietary habits due to urbanization, upsurge of confectionary food outlet rich in refined carbohydrate, low fiber content and fresh fruit which lead to increase fecal transit time. ${ }^{11}$ Our recent study indicates

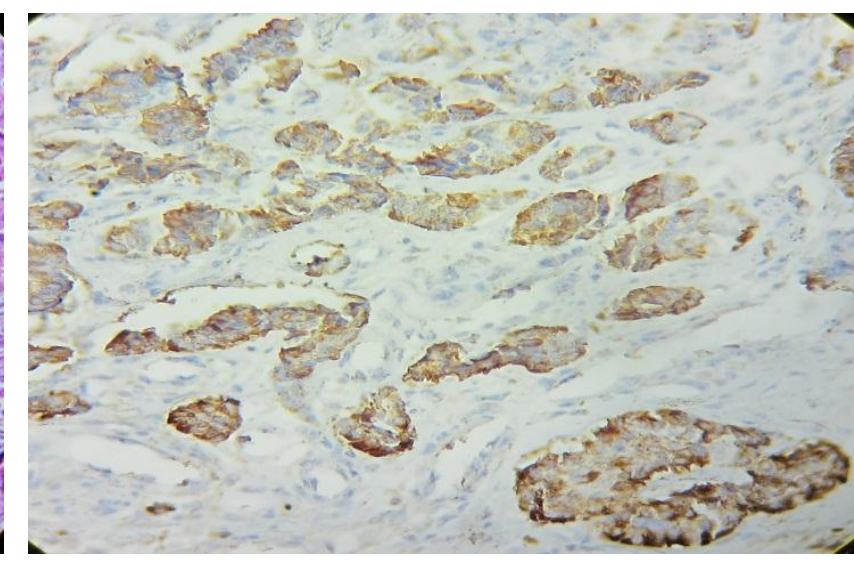

Fig 2: IHC staining showing synaptophysin positivity in carcinoid appendix (40x)

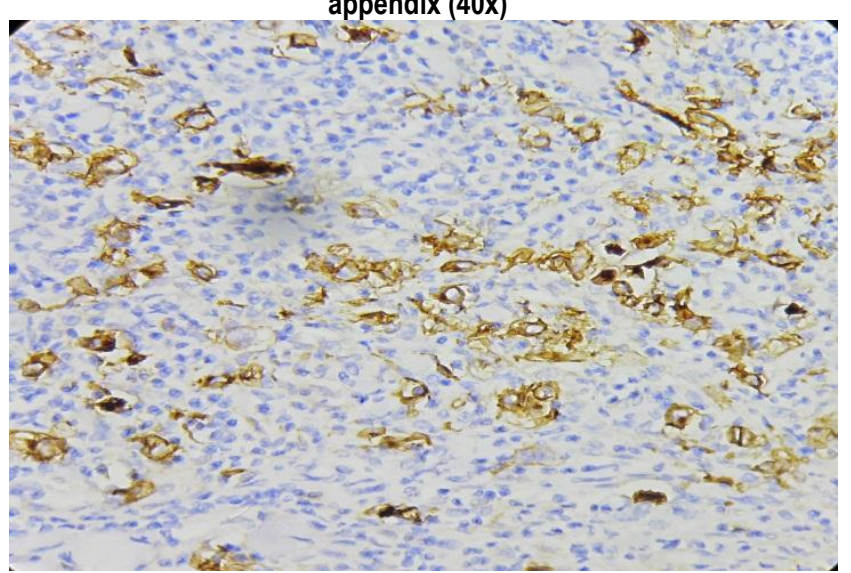

Fig 4: IHC showing CD30 positivity in RS cells (40x)

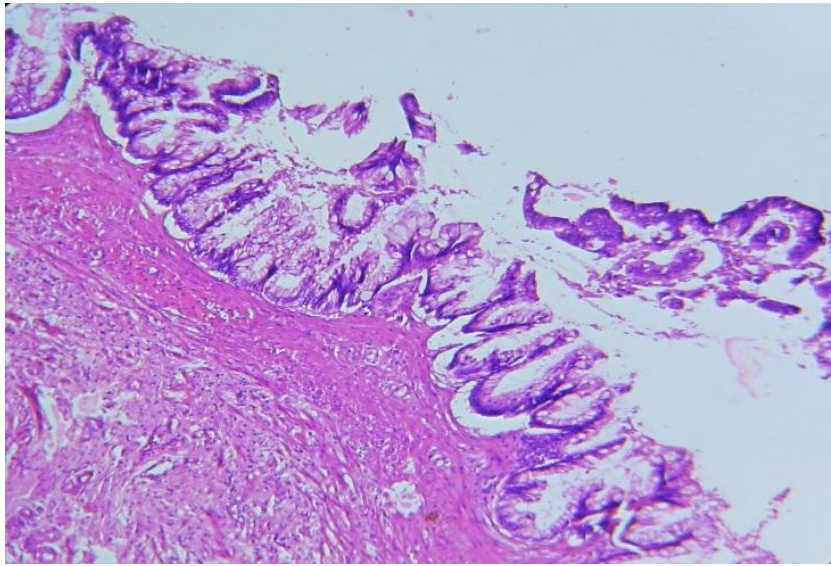

Fig 6: Low grade appendiceal mucinous adenocarcinoma (10x)

increasing incidence of malignancies and decreasing age, which is also observed by various study in other developing countries. ${ }^{11}$ Out of 145 cases, commonest malignancy was adenocarcinoma, $110(75.9 \%)$ cases, followed by Squamous cell carcinoma, 18 cases. Most of adenocarcinoma presented in colon and rectum whereas squamous cell carcinoma in esophagus, which correlates well with other studies.1,10,12 Majority of adenocarcinomas were moderately differentiated type (72.6\%) which was comparable with study by Halder KS et al. ${ }^{12}$

Esophageal Cancer is the 8th common cancer in world. ${ }^{3}$ It is a catastrophic disease due to rapid progression and poor prognosis. In our study, esophageal cancer constituted $14.5 \%$ of all tumors studied which was lower than those found by Patel MM et al $(38.93 \%)^{10}$. Squamous cell carcinoma is most common in esophagus and majorities were located in lower third of 
esophagus (61.9\%). Our findings correlate with study of Cherian JV et al in Tamil Nadu (South India). ${ }^{13}$ Higher rate of Squamous cell carcinoma in Indian sub-continent may be related to tobacco chewing, smoking, alcohol abuse and ingestion of hot and spicy food which are mostly change able risk factor.

In stomach, 23 cases of malignancy were noted, out of which 21 cases were of adenocarcinoma, one case each of GIST and carcinoid. Majority of tumors were located at pylorus (56.5\%) followed by body (34.7\%) of stomach which correlates with study by Nandi A et al. ${ }^{14}$

Though small intestine represents maximum surface area in gastrointestinal tract, small bowel neoplasm is rare compared to esophagus \& colorectal carcinoma This may be due to decrease in mechanical and chemical inflammation of mucosa because of liquidity and alkaline $\mathrm{PH}$ of small bowel content, rapid transit time thereby shorter contact time with luminal carcinogens and protective lymphoid tissue network in small bowel. ${ }^{15} 31$ cases $(21.4 \%)$ of small intestine cancer were studied which correlates with study by Purohit MB et al $(16.32 \%)^{1}$ and are more than those found by Patel $\mathrm{MM}$ et al $(6.56 \%) .{ }^{10}$ Adenocarcinoma was commonest type (22 cases) followed by GIST (4 cases) and a single case of Malignant Melanoma .Small intestine is common site for gastrointestinal lymphoma and in this study $3 \mathrm{NHL}$ were noticed and 1 rare case of Hodgkin's Lymphoma was also reported (ileum).

Two rare cases of low grade appendiceal mucinous adenocarcinoma were also noted in the study period.

The incidence of Colon and Rectal Cancer is higher in developed countries than in the developing countries. These geographic differences represent the effect of different dietary habits. In our study colon and rectum was commonest site, 58 cases (40\%), of GI malignancies which correlates with the study by Purohit MB et al $(48.9 \%)^{1}$ and Patel $\mathrm{MM}$ et al $(32.8 \%) .^{10}$

Majority were adenocarcinoma (54 cases), Malignant Melanoma (2 cases), NHL (1 case). Furthermore, one rare case of Metastatic carcinoma in colon was reported in a patient who was a known case of papillary renal cell carcinoma. IHC was performed and the malignant cells were positive for vimentin and CD10 which points in favor of metastasis from renal cell carcinoma.

In current study 8 cases of anal malignancies were seen with female preponderance which correlates with study by Karaitianos IG et al. 8

\section{CONCLUSION}

Gastrointestinal malignancies were common in 46-60 years of age with overall male preponderance; large intestine was the commonest site and adenocarcinoma the commonest histopathological diagnosis. However comparisons with other similar studies and data shows an array of histological patterns, varied clinical presentations, an assortment of gross patterns and an immense variability in their prognosis with marked epidemiological differences in various geographic and ethnic populations.

\section{REFERENCES}

1. Purohit DMB, Purohit DTM, Gandhi DSH, Dobaria DRD. Histopathological diagnosis Of Gastro intestinal malignancies- A retrospective study. NJIRM. 2013; 4(2):107-112.
2. Steward BW, Wild CP. World Cancer Report. Lyon: IARC Press; 2014. Press release N0224.

3. Napier KJ, Scheerer M, Misra S. Esophageal cancer: A Review of epidemiology, pathogenesis, staging workup and treatment modalities. World Journal of Gastrointestinal Oncology. 2014; 6(5):112-120.

4. Crawford JM, Liu C. Robbins and Cotran Pathologic Basis of Disease.7th ed. Noida:Elsevier India Private Limited;2004.797-875.

5. Gabbert HE, Shimoda T, Hinaut $P$, Nakamura $Y$, Field TK, Inone H. WHO Classification of Tumors. In: Pathology and Genetics of Tumors of the Digestive Systems.Lyon: IARC Press; 2000. 11-30.

6. Radovanovic D, SteyVanovic D, Pavlovic I, Jasarovic D, Mitovic N, Ilic I. Gastrointestinal stromal tumors of Gaster-case report. Med. Pregl.2008; 61(7):409-413.

7. Basnet RB, Amartya B, Siwakoti YC. et al. Histopathological diagnosis of Gastrointestinal malignancies in Bir Hospital. PMJN.2009; 8(2): 51-57.

8. Karaitianos IG, Koundouris C. Malignant tumors of the anal canal: a comprehensive review. Annals Of Gastroenterology.2001;14(1):2732.

9. Dabaja BS, Suki D, Pro B, Bonnen M, Ajani J. Adenocarcinoma of the small bowel. J Cancer.2004;101:518-526.

10. Patel MM, Gamit B, Patel PR. Analysis of Gastrointestinal Malignancy: A 5 Years Study. Natl J Community Med. 2012; 3(3):555557.

11. Khurshed A, Ahmed R, Bhurgri Y. Primary Gastrointestinal Malignancies in childhood and Adolescence - an Asian Perspective. Asian Pac J Cancer prev. 2007; 8:613-617.

12. Halder KS, Bhattacharjee KP, Bhar $P$, Pachaury A, Biswas RR, Majhi $T$, et al. Epidemiological, Clinico-Pathological Profile and Management of Colorectal Carcinoma in a Tertiary Referral Center of Eastern India. JKIMSU.2013 ; 2(1):45-50.

13. Cherian JV, Sivaraman R, Muthusamy AK, Jayanti V. Carcinoma of the Esophagus in Tamil Nadu (South India): 16-year Trends from a Tertiary Center. J Gastrointestin Liver Dis. 2007; 16(3): 245-249.

14. Nandi A, Biswas PK, Kar M, Sinha SK. Clinicopathological profile of gastric cancer in a tertiary care hospital in Eastern India: $A$ prospective 2 year study. Clin Cancer Investig J.2014; 3:14-20.

15. Hatzaras I, Palety JA, Abir F, Sullivan P, Kozol RA, Dudrick SJ, Longo WE. Small Bowel Tumors Epidemilogic and Clinical Characteristics of 1060 Cases From the Connecticut Tumor Registry. (Reprinted)Arch Surg.2007; 142(3):229-235.

\section{Source of Support: Nil.}

Conflict of Interest: None Declared.

Copyright: (c) the author(s) and publisher. IJMRP is an official publication of Ibn Sina Academy of Medieval Medicine \& Sciences, registered in 2001 under Indian Trusts Act, 1882.

This is an open access article distributed under the terms of the Creative Commons Attribution Non-commercial License, which permits unrestricted non-commercial use, distribution, and reproduction in any medium, provided the original work is properly cited.

Cite this article as: Ankita Kakani, Ajay Yadav. Clinico-Pathological Spectrum of Gastrointestinal Malignancies in Jaipur Region. Int J Med Res Prof. 2016; 2(3):127-30. 